\title{
All hands on deck
}

\author{
Reforms in science teaching are building a stronger, more flexible student population ready to face \\ the challenges of the future. We must remove the barriers that prevent these talented students from \\ entering the geosciences.
}

Many of the great challenges that humanity is faced with can only be resolved with scientific input. Degrading air, soil and water quality, hazards from extreme weather, earthquakes and volcanoes, and climate change are complex and multifaceted problems. Tackling them successfully often requires geoscientists to work differently than they might have done in the past. Educators, in response, are realizing that the way science is taught needs a revamp. As noted in a joint special focus from Nature and Scientific American (www.nature.com/stem), science teachers at all levels are moving away from the lecture and towards higher-order learning that encourages the development of critical thinking, problem solving and communication skills. These are welcome developments that will build both a strong scientific workforce and science literacy among the general public. But the full potential of these reforms will not be realized if the scientific workforce is only pulled from a narrow subsection of the global population. In this issue and an accompanying web focus (http://www.nature.com/ngeo/focus/ geoscience-accessibility/index.html), we look at the ways that students from an array of backgrounds and physical abilities can be attracted to and retained in the geosciences.

As with many STEM (science, technology, engineering and mathematics) disciplines, careers in the geosciences have historically been dominated, at least in the West, by ablebodied white men: indeed, the archetypal geoscientist is a wiry male armed with a rucksack and rock hammer who climbs mountains and hacks at rocks well into his seventies. Over the past few decades some efforts have been made in diversification, particularly in degree attainment by women and ethnic minorities ${ }^{1}$ and in expanding geoscience resources into lower-income countries ${ }^{2}$. But tremendous amounts of work still remain: barriers to entry to the geosciences remain at many levels.

Children who grow up near large parks or forests may develop an interest in the natural environment from an early age. For those with limited exposure, strong primary and secondary teaching is key to growing a life-long interest in the geosciences. In the

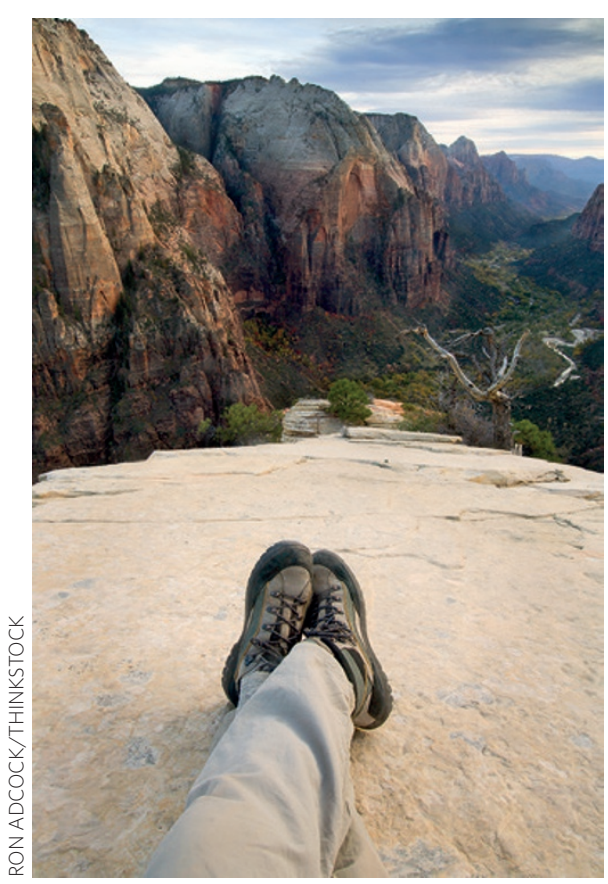

past, such lessons might have been limited to a rock box and a poster of cloud types, outreach programmes that place teachers on research ships or enable teachers and students to take part in ongoing research projects ${ }^{3}$ now allow for a more engaging learning experience. On page 576, Fung et al. describe an activity designed to increase climate literacy and meet some of the Next Generation Science Standards in the US. Using dynamic approaches to learning not only builds a future generation of scientists, but also increases science literacy among schoolchildren who do not go on to pursue STEM careers.

Those who do choose further study in the geosciences will face yet more hurdles at university. For many undergraduates, one of the most daunting is the fieldwork component that many Earth Science degree programmes require. For some, this is the first time that they have been camping or even relieved themselves outdoors, which has been reported as a significant source of anxiety ${ }^{4}$. Other students have physical limitations that hinder their ability to fully participate. This is not limited to the traditional field camp: many degrees in physical oceanography require several weeks aboard a ship - a task that is difficult for those who suffer from severe seasickness. Fieldwork is certainly an important component of some areas of research in the geosciences, but may be unnecessary in others that rely primarily on experimental or remote sensing data or on numerical modelling. Offering adaptations to the field component of classes, like those Gilley et al. describe on page 579 , ensures that students are not pushed out of topics that they can contribute to simply because of the physical demands of prerequisite courses.

Retention of a diverse group of students beyond their undergraduate degree is a further challenge that must be met by our community. Entering an academic world where few people share your background is an additional struggle. Here, as Rebecca Haacker reports on page 577, mentoring seems to be a successful path towards retention and promotion of students from minority backgrounds. She describes a formal mentoring programme, but informal peer mentoring networks, such as the Earth Science Women's Network, have also been shown to build the confidence of participants and allow mentees to confront barriers to career advancement ${ }^{5}$.

The geosciences are at the forefront of some of the biggest problems faced by society. In war movies, as the enemy approaches the heroes' ship, the call goes out "all hands on deck". Our scientific challenges may not produce the same rush of adrenaline as the roar of enemy jet engines, but they are no less an existential threat, albeit over longer timescales. In order to meet these challenges, we need to ensure that we have the best scientists at work, supported by an educated voting public. To do so we must tear down the barriers that prevent people from engaging with and advancing in the geosciences.

\footnotetext{
References

1. Holmes, M.A., O'Connell, S., Frey, C. \& Ongley, L. Nature Geosci. 1, 79-82 (2008)

2. Hewitson, B. Nature Geosci. 8, 497-499 (2015).

3. Murray, L. Eos 96, http://dx.doi.org/10.1029/2015EO032145 (2015).

4. Jarvis, S. Prof. Geol. 52, 40-41 (2015)

5. Adams, A. S., Steiner, A. L. \& Wiedinmyer, C. Bull. Am. Meteorol. Soc. http://dx.doi.org/10.1175/ BAMS-D-15-000401 (2015).
} 